\title{
Jean Paulhan et les poètes. Textes réunis par Claude- Pierre Pérez. Actes du colloque de Nice, 13-14 mars 2003
}

\section{Emanuele Kanceff}

\section{(2) OpenEdition Journals \\ Edizione digitale \\ URL: http://journals.openedition.org/studifrancesi/33596 \\ DOI: $10.4000 /$ studifrancesi.33596 \\ ISSN: 2421-5856 \\ Editore \\ Rosenberg \& Sellier}

\section{Edizione cartacea}

Data di pubblicazione: 1 décembre 2005

Paginazione: 674

ISSN: 0039-2944

\section{Notizia bibliografica digitale}

Emanuele Kanceff, «Jean Paulhan et les poètes. Textes réunis par Claude-Pierre Pérez. Actes du colloque de Nice, 13-14 mars 2003», Studi Francesi [Online], 147 (XLX | III) | 2005, online dal 30 novembre 2015, consultato il 18 avril 2021. URL: http://journals.openedition.org/studifrancesi/33596 ; DOI: https://doi.org/10.4000/studifrancesi.33596

Questo documento è stato generato automaticamente il 18 avril 2021.

\section{cc) $($ ) $\ominus$}

Studi Francesi è distribuita con Licenza Creative Commons Attribuzione - Non commerciale - Non opere derivate 4.0 Internazionale. 


\title{
Jean Paulhan et les poètes. Textes réunis par Claude-Pierre Pérez. Actes du colloque de Nice, 13-14 mars 2003
}

\author{
Emanuele Kanceff
}

\section{NOTIZIA}

AA. VV., Jean Paulhan et les poètes. Textes réunis par Claude-Pierre Pérez. Actes du colloque de Nice, 13-14 mars 2003, Aix-en-Provence, Publications de l'Université de Provence, 2004 («Textuelles littérature»), pp. 198.

1 Nel periodo tra il primo dopoguerra e gli anni Sessanta del Novecento Jean Paulhan è stato in contatto con tutti i poeti francesi e molti di altri paesi, come il Belgio, nelle forme più svariate, come lettore, consigliere, editore, obiettore, talvolta avversario, spesso amico. Questa sua presenza è stata per molti di loro importante, e senza di lei numerose opere non avrebbero visto la luce. I saggi qui raccolti intendono fare nuova luce su queste circostanze "capitali" per la poesia del Novecento. come spiega Claude-Pierre PÉREZ nel suo Avant-propos.

2 Il volume è suddiviso in alcune sezioni, che si completano a vicenda. Nella prima, Le lecteur, l'éditeur, Anne Kimball illustra i rapporti con Jacob (Apollon et 1'insaisissable Protée. Jean Paulhan et Max Jacob) e Florence DAVAILlE quelli con Supervielle (Jean Paulhan-Julio Supervielle: quel(s) lieu(x) commun(s) ?). La seconda sezione (Des contemporains capitaux) presenta gli interventi di Brigitte OUVRY VIAL, che si occupa di Michaux (Henry Michaux-Jean Paulhan: conversation, monologue et contrepoint), e di Michel Collot, che s'interessa di Ponge (Le petit poisson et le maitre nageur. Jean Paulhan et Francis Ponge). In Le Surréalisme et ses entours, che forma la terza sezione, si leggono i contributi di Colette Guedj su Éluard (Eluard au(x) miroir(s) de Paulhan); di Olivier PENOT-LACASSAGNE 
su Artaud (Artaud et Paulhan, entre fiction et vérité), e di Adriano MARCHETTI su Bousquet (Jean Paulhan et Joë Bousquet: «seuls tous deux en France»). La quarta sezione, Découvreur ou créateur ?, presenta la ricostruzione di un malinteso, ad opera di Christophe CHABBERT (Chazal-Paulhan: histoire d'un malentendu) ma anche quella di una relazione non priva di spine ma fertile e feconda, quella con Catherine Pozzi, che Françoise SIMONET-TENANT s'incarica di rievocare (Jean Paulhan: le «jardinier créateur» de Catherine Pozzi). Rimaneva da gettare uno sguardo oltre confine: nell'ultima sezione, Hors de France, Bernard BaIllaud si occupa del Belgio (De "Disque vert" en Cobra: Jean Paulhan avec les Belges) e Alain PAIRE dell'Italia (Jean Paulhan et Giuseppe Ungaretti: "une fraternité de chaque instant»).

3 In un brillante Envoi, che non vuol fare da conclusione, Claude-Pierre PÉREz rievoca l'episodio del Tableau de la poésie en France che Paulhan lanciò nel 1933 attraverso le pagine della rivista e ne cerca le ragioni "politiche". 